\title{
Editorial
}

\section{The Ho Chi Minh City Society of Dialysis Therapies}

\author{
Pham Van Bui \\ Pham Ngoc Thach University of Medicine, Nguyen Tri Phuong University Hospital, Ho Chi Minh City, Vietnam
}

On behalf of the members of the Ho Chi Minh City Society of Dialysis Therapies (HSDT), I am honored that our society has now become officially affiliated with the highly respected international journal Blood Purification.

Launched in 2015, HSDT is the youngest professional society in the field of dialysis in Vietnam. Our affiliation with Blood Purification will help us in achieving our goals of internationalizing the society, updating and improving our knowledge, and participating in the sharing of knowledge and experiences among the journal's global readership. Our 1,000 or so official members, predominantly nurses and practitioners working in nephrology and dialysis departments, can also benefit by learning more about how to conduct and write on research.

Our society's goals are patient-centered, aimed at improving the quality of life for patients on dialysis. To achieve this, there are many areas we need to work on. These include improving our clinical knowledge and practice by undergoing CME courses and learning from the international community, so that we can offer better patient care; introducing guidelines for the care of kidney patients based on international guidelines, particularly those of the Japanese Society for Dialysis Therapy (JSDT); educating dialysis patients in self-care; acting as a bridge

\section{KARGER}

(c) 2018 S. Karger AG, Basel

E-Mail karger@karger.com

www.karger.com/bpu between the relevant societies and associations to share our experiences in Vietnam and learn from each other; promoting multidisciplinary care and research among related specialties such as endocrinology, cardiology and urology; cooperating with international societies and associations to conduct research; and consulting to advance healthcare policy for the prevention of kidney disease and the provision of improved care for kidney patients. Our affiliation with the journal will help us in our efforts to achieve these goals.

Our society has much to be thankful for. I would like to take this opportunity to especially thank our Japanese colleagues from JSDT and the Tanaka Urologic Clinic for their encouragement and support in our society's establishment, their sponsorship of our trips to Japan to attend and share experiences with colleagues from many countries at the JSDT annual congresses, their cooperation and support in establishing the Japanese-Standard Dialysis Center, which is currently the only one in Vietnam with advanced dialysis technology, and their sponsorship of trips for our doctors to receive training in Japan. Just in a short time, we have gained so much in our practice and have been able to provide high-quality dialysis to our patients because of such international coop- 
eration. We want to actively develop on these opportunities still further with the noble objective of improving our knowledge and skills so that we can serve our patients better.

Through our affiliation with Blood Purification, we will not only learn from the knowledge offered by experienced practitioners and researchers publishing their content in the journal but also work towards publishing such high-quality articles. Already, I have personally had the experience of publishing articles in Blood Purification in the 2017 supplement entitled "Current Status and Challenges of Dialysis in Asian Countries" [1]. With support from a professional medical writer and editor, I published a case report that meets the international reporting guidelines for case reports (CARE guidelines) and a summary report of the status of dialysis in Vietnam (in the innova- tive form of infographics). My colleagues in HSDT and I look forward to reporting further on our work in Vietnam and increasing our participation in the international community.

\section{Acknowledgement}

The author thanks Caryn Jones of ThinkSCIENCE, Tokyo, Japan for the support she has extended in writing this article.

Reference

1 Kawanishi H, Hyodo T: Current status and challenges of dialysis in Asian countries. Blood Purif 2017;44(suppl 1):1-62. 